BMJ Open

Diabetes

Research

\& Care

\title{
Factors determining chance of type 2 diabetes remission after Roux-en-Y gastric bypass surgery: a nationwide cohort study in 8057 Swedish patients
}

\author{
Erik Stenberg (D) , ${ }^{1}$ Torsten Olbers, ${ }^{2,3}$ Yang Cao (D) , ${ }^{4}$ Magnus Sundbom (D) , \\ Anders Jans (D) , ${ }^{1}$ Johan Ottosson, ${ }^{1}$ Erik Naslund, ${ }^{6}$ Ingmar Näslund (i) ${ }^{1}$
}

To cite: Stenberg $\mathrm{E}$, Olbers T, Cao Y, et al. Factors determining chance of type 2 diabetes remission after Rouxen-Y gastric bypass surgery: a nationwide cohort study in 8057 Swedish patients. BMJ Open Diab Res Care 2021;9:e002033. doi:10.1136/ bmjdrc-2020-002033

- Supplemental material is published online only. To view, please visit the journal online (http://dx.doi.org/10.1136/ bmjdrc-2020-002033).

Received 23 November 2020 Revised 19 April 2021 Accepted 2 May 2021
Check for updates

(C) Author(s) (or their employer(s)) 2022. Re-use permitted under CC BY. Published by BMJ.

For numbered affiliations see end of article.

Correspondence to Dr Erik Stenberg; erik.stenberg@regionorebrolan. se

\section{ABSTRACT}

Introduction Bariatric and metabolic surgery is an effective treatment option for type 2 diabetes (T2D). Increased knowledge regarding factors associated with diabetes remission is essential in individual decision making and could guide postoperative care. Therefore, we aimed to explore factors known to affect the chance of achieving diabetes remission after bariatric and metabolic surgery and to further investigate the impact of socioeconomic factors.

Research design and methods In this nationwide study, we assessed all patients with T2D who underwent Roux-en-Y gastric bypass (RYGB) surgery between 2007 and 2015 in the Scandinavian Obesity Surgery Registry. Remission was defined as absence of antidiabetic medication for T2D 2 years after surgery. Multivariable logistic regression was used to evaluate factors associated with diabetes remission, with missing data handled by multiple imputations.

Results A total of 8057 patients were included. Mean age \pm SD was $47.4 \pm 10.1$ years, mean body mass index $42.2 \pm 5.7 \mathrm{~kg} / \mathrm{m}^{2}$, mean hemoglobin A1c $59.0 \pm 17.33$, and $61.7 \%(n=4970)$ were women. Two years after surgery, 6211 (77.1\%) patients achieved T2D remission. Preoperative insulin treatment (OR $0.26,95 \% \mathrm{Cl} 0.22$ to 0.30), first-generation immigrant (OR $0.66,95 \% \mathrm{Cl} 0.57$ to 0.77 ), duration of T2D (OR $0.89,95 \% \mathrm{Cl} 0.88$ to 0.90 ), dyslipidemia (OR $0.71,95 \% \mathrm{Cl} 0.62$ to 0.81 ), age (OR 0.97 , $95 \% \mathrm{Cl} 0.96$ to 0.97 ), and high glycosylated hemoglobin A1c (HbA1c) (OR 0.99, 95\% Cl 0.98 to 0.99) were all associated with lower T2D remission rate. In contrast, residence in a medium-sized (OR 1.39, 95\% $\mathrm{Cl} 1.20$ to 1.61) or small (OR 1.46, $95 \% \mathrm{Cl} 1.25$ to 1.71) town and percentage of total weight loss (OR 1.04, 95\% Cl 1.03 to 1.04) were associated with higher remission rates. Conclusion Among patients with T2D undergoing RYGB surgery, increasing age, $\mathrm{HbA} 1 \mathrm{C}$, and diabetes duration decreased the chance of reaching diabetes remission without cut-offs, while postoperative weight loss demonstrated a positive linear association. In addition, being a first-generation immigrant and living in a large city were socioeconomic factors having a negative association.

\section{INTRODUCTION}

Type 2 diabetes (T2D) is a major threat to public health, with an estimated global

\section{Significance of this study}

What is already known about this subject?

- While bariatric and metabolic surgery offers a high chance of diabetes remission, previous studies have primarily evaluated factors associated with remission when separated into prespecified categories.

- The contribution of socioeconomic factors is incompletely investigated.

What are the new findings?

- Factors with known association with diabetes remission had a linear inverse relationship with type 2 diabetes (T2D) remission without clear cut-off.

- Socioeconomic factors were relevant for diabetes remission.

How might these results change the focus of research or clinical practice?

- The results of the study add to the body of literature supporting bariatric and metabolic surgery for patients with severe obesity and T2D.

prevalence of $9.8 \%$ in men and $9.2 \%$ in women. ${ }^{1}$ A high but stable incidence of T2D has been reported in many countries in recent years, ${ }^{2}$ and obesity remains one of the strongest risk factors for T2D. ${ }^{3}$ In addition, diabetes has been reported to be the second major body mass index (BMI)-related cause of death, accounting for approximately 0.9 million deaths annually worldwide. ${ }^{4}$

Currently, bariatric and metabolic surgery is associated with a low risk of serious complications and side effects, and well-documented long-term weight loss and improvements in many relevant obesity-related comorbidities. $^{5-7}$ The benefits of surgery appear to be particularly high for patients with T2D, where diabetes remission is common. ${ }^{5} 89$ Although diabetes relapse occurs in the long run, surgical treatment reduces the risk of 
diabetes complications and reduces the cost of healthcare. $^{58-11}$

Despite the excellent results of bariatric and metabolic surgery, only a small proportion of eligible patients with T2D are evaluated for this treatment. ${ }^{12}$ Furthermore, there is often limited access to surgery based on perceived low rates of $\mathrm{T} 2 \mathrm{D}$ remission in older patients and advanced disease. Improved knowledge on factors associated with the chance of remission would enable us to properly inform patients who may benefit from bariatric and metabolic surgery.

Duration of diabetes, glycemic control, use of insulin, older age, and degree of postoperative weight loss have all been reported as factors influencing the chance of diabetes remission. ${ }^{813-15}$ However, most of these factors have been evaluated with cohorts divided into categories, often leading to some cut-off values for bariatric and metabolic surgery indications. One example is the recommendation of a 10-year duration of diabetes limit suggested by the British National Institute for Health and Care Excellence. ${ }^{16}$ Recent data have suggested a more linear relationship between diabetes remission and diabetes duration in a cohort with a duration from 0 to 26 years, bringing into question recommendations based on specific thresholds. ${ }^{13}$

Socioeconomic factors generally viewed as indicators of a low socioeconomic status are known to increase the incidence of T2D, in particular in high-income countries. ${ }^{17}$ Recent studies have also reported an association between several socioeconomic factors and the risk for complications, as well as the effect on weight loss and improvements in health-related quality of life after bariatric surgery. ${ }^{18-20}$ However, the effect of socioeconomic factors on remission rates of T2D after bariatric surgery remains unknown.

This study aimed to explore further preoperative factors known to affect the chance of achieving diabetes remission after bariatric and metabolic surgery and to investigate the impact of socioeconomic factors.

\section{METHODS}

The Scandinavian Obesity Surgery Registry (SOReg) is a national research and quality database covering virtually all bariatric and metabolic surgical procedures in Sweden. $^{21}$ By using personal identification numbers (unique to all Swedish citizens), the SOReg database was linked to the Swedish National Patient Register, the Swedish National Death Register, the Swedish Prescribed Drug Register, and Statistics Sweden. These registers cover inpatient and outpatient hospital visits, mortality, drugs prescribed, and individual socioeconomic data. All patients who underwent a primary bariatric and metabolic surgical procedure (Roux-en Y gastric bypass or sleeve gastrectomy) between 2007 and 2015 and registered in the SOReg were considered for inclusion. Only patients diagnosed with T2D, as defined by the American Diabetes Association (ie, fasting plasma glucose $\geq 126 \mathrm{mg} / \mathrm{L}(7.0 \mathrm{mmol} / \mathrm{L})$, glycosylated hemoglobin A1c (HbAlc) $\geq 48 \mathrm{mmol} / \mathrm{mol}(6.5 \%)$, or medical treatment for diabetes), operated with a primary Roux-en-Y gastric bypass (RYGB) procedure were included in the study. ${ }^{22}$

The SOReg reports metabolic obesity-related diseases, defined as medical treatment for a specific metabolic obesity-related disease (diabetes, hypertension, dyslipidemia, dyspepsia/gastroesophageal reflux disease, and depression), and nocturnal continuous positive airway pressure treatment for sleep apnea. Since cardiovascular comorbidity is not a mandatory variable in the SOReg, data on this comorbidity were based on combined data from the Swedish National Patient Register and the SOReg, defined as a history of ischemic heart disease, angina pectoris, cardiomyopathy, cardiac failure, or cardiac arrhythmia. Diabetes duration was based on a combination of data from the SOReg, the Swedish National Patient Register, and the Swedish Prescribed Drug Register, while HbA1c values were reported at predefined outpatient visits. SOReg data are prospectively collected at baseline about 1 month before surgery, and on day 30 and at 1, 2, 5, and 10 years after surgery. Most registrations are based on information from consultations at the outpatient clinic. When this is not possible, follow-ups are based on telephone, e-meetings, or written response, with blood samples and weights registered from primary care or a different hospital outpatient clinic.

Educational level was divided into four categories based on the highest completed education at the time of surgery: primary education ( $\leq 9$ years of schooling), secondary education (completed 10-12 years of schooling), higher education $\leq 3$ years (completed college or university degree with $\leq 3$ years of education), and higher education $>3$ years. Disposable income (total taxable income minus taxes and other negative transfers) was divided into percentiles (lowest 20th, 20th to median, median to 80th, and highest 80th) based on the disposable income of all adults in Sweden during the year of surgery. Place of residence was divided into three categories, following definitions used by the Swedish Association of Local Authorities and Regions: large city (>200000 inhabitants) or municipality near a large city; medium-sized town ( $\geq 50000$ inhabitants) or municipality near a medium-sized town; and smaller town or urban area $(<50000$ inhabitants) or rural municipality. Heritage was divided into three categories based on the country of birth and parents' place of birth, as described previously. $^{18}$

Postoperative weight loss at 2 years after surgery was presented as change in BMI (BMI loss=initial BMI-postoperative $\mathrm{BMI}$ ), percentage of total weight loss $(\mathrm{TWL}=100 \times$ weight loss/preoperative weight), and percentage of excess BMI loss $(\mathrm{EBMIL}=100 \times$ [initial BMI-postoperative $\mathrm{BMI}] /$ initial BMI-25]). All baseline values were evaluated before preoperative weight reduction.

Postoperative complications were classified according to the Clavien-Dindo classification of postoperative complications, with any complication defined as Clavien-Dindo 
Table 1 Baseline characteristics of the study group

\begin{tabular}{|c|c|c|c|c|c|}
\hline & \multirow[b]{2}{*}{ Missing values (\%) } & \multirow{2}{*}{$\begin{array}{l}\text { Entire group } \\
\mathrm{n}(\%), \text { mean } \pm \text { SD }\end{array}$} & \multirow{2}{*}{$\begin{array}{l}\text { Remission } \\
\text { n (\%), mean } \pm \text { SD }\end{array}$} & \multirow{2}{*}{$\begin{array}{l}\text { Non-remission } \\
\text { n (\%), mean } \pm \text { SD }\end{array}$} & \multirow[b]{2}{*}{$P$ value } \\
\hline & & & & & \\
\hline Age, years & 0 & $47.4 \pm 10.08$ & $46.6 \pm 10.2$ & $51.7 \pm 8.7$ & $<0.001$ \\
\hline Female & & $4970(61.7)$ & $3891(62.6)$ & $1079(58.5)$ & Ref \\
\hline Male & & 3087 (38.3) & $2320(37.4)$ & 767 (41.5) & 0.001 \\
\hline $\mathrm{BMI}, \mathrm{kg} / \mathrm{m}^{2}$ & 0 & $42.2 \pm 5.74$ & $42.5 \pm 5.8$ & $41.2 \pm 5.4$ & $<0.001$ \\
\hline Diabetes duration & 0 & $3.7 \pm 4.59$ & $2.7 \pm 3.6$ & $7.2 \pm 5.8$ & $<0.001$ \\
\hline $\begin{array}{l}\text { Glycosylated hemoglobin A1c, } \\
\mathrm{mmol} / \mathrm{mol}\end{array}$ & $1068(13.3)$ & $59.0 \pm 17.33$ & $56.7 \pm 16.5$ & $67.3 \pm 17.5$ & $<0.001$ \\
\hline Dyslipidemia & & $2527(31.4)$ & $1663(26.8)$ & $864(46.8)$ & $<0.001$ \\
\hline Dyspepsia/GERD & & $1031(12.8)$ & 761 (12.3) & $270(14.6)$ & 0.007 \\
\hline Depression & & $1297(16.1)$ & 986 (15.9) & $311(16.8)$ & 0.318 \\
\hline Sleep apnea & & 1529 (19.0) & $1146(18.5)$ & $383(20.7)$ & 0.027 \\
\hline Hypertension & & $4546(56.4)$ & 3259 (52.5) & $1287(69.7)$ & $<0.001$ \\
\hline Cardiovascular comorbidity & & $917(11.4)$ & $612(9.9)$ & $305(16.5)$ & $<0.001$ \\
\hline Education & $55(0.7)$ & & & & \\
\hline Primary education $\leq 9$ years & & 1606 (19.9) & $1214(19.7)$ & $392(21.4)$ & 0.219 \\
\hline Secondary education & & $4762(59.1)$ & $3671(59.5)$ & $1091(59.5)$ & Ref \\
\hline >80th percentile & & $958(11.9)$ & $714(11.6)$ & $244(13.4)$ & 0.035 \\
\hline Residence & $31(0.4)$ & & & & \\
\hline Large city or municipality & & $2734(33.9)$ & $2047(33.1)$ & $687(37.2)$ & Ref \\
\hline Medium-sized town or municipality & & $3061(38.0)$ & $2390(38.7)$ & $671(36.4)$ & 0.004 \\
\hline $\begin{array}{l}\text { Small town, urban area, rural } \\
\text { municipality }\end{array}$ & & $2231(27.7)$ & $1744(28.2)$ & $487(26.4)$ & 0.007 \\
\hline Heritage & $18(0.2)$ & & & & \\
\hline $\begin{array}{l}\text { Swedish-born, Swedish } \\
\text { descendant }\end{array}$ & & $6072(75.4)$ & 4727 (76.3) & 1345 (72.9) & Ref \\
\hline $\begin{array}{l}\text { Swedish-born, non-Swedish } \\
\text { descendant }\end{array}$ & & $338(4.2)$ & $267(4.3)$ & $71(3.8)$ & 0.621 \\
\hline Born outside Sweden & & 1629 (20.2) & $1200(19.4)$ & 429 (23.3) & $<0.001$ \\
\hline
\end{tabular}

*Median (interquartile range).

BMI, body mass index; GERD, gastroesophageal reflux disease; Ref, reference.

$\geq 1$ (ie, any deviation from a normal postoperative course). ${ }^{23}$ Specification of the severity of complications was introduced in the SOReg in 2010, and serious postoperative complications (defined as Clavien-Dindo $\geq 3 \mathrm{~b}$, ie, need for intervention requiring general anesthesia or intensive care due to single-organ or multiorgan failure, or mortality) were analyzed for patients operated after 2010.

\section{Outcomes}

The main outcome was remission of diabetes 2 years after surgery. Remission was defined as being without diabetes 


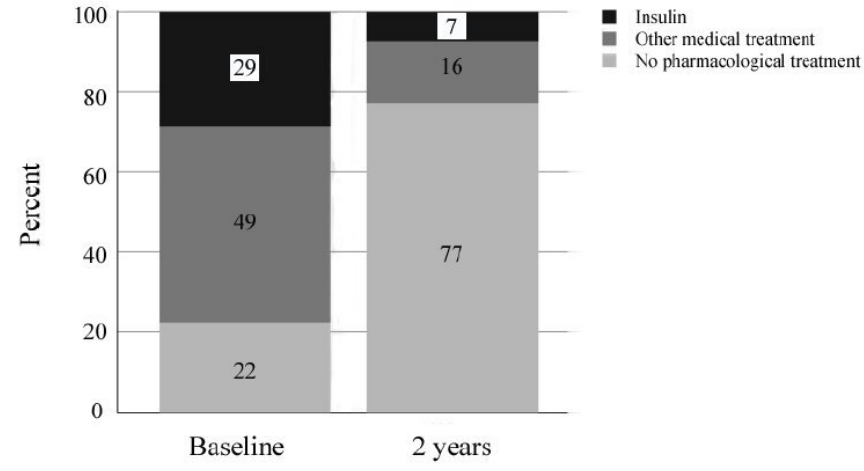

Figure 1 Use of antidiabetic drugs before and at 2 years after surgery. Percentage of all patients $(\mathrm{N}=8057)$ at each point.

medication within a time frame of \pm 6 months, ie, $18-30$ months postoperatively. Secondary outcomes were complete or partial remission of diabetes. Complete remission was defined as an $\mathrm{HbAlc}$ value $\leq 42 \mathrm{mmol} / \mathrm{mol}$ without medical treatment, and partial remission was defined as an HbAlc value $\leq 48 \mathrm{mmol} / \mathrm{mol}$ without medical treatment. ${ }^{24}$

\section{Statistics}

Categorical data are presented as numbers (n) and percentages $(\%)$, and continuous variables as mean $\pm \mathrm{SD}$. Univariable, conditional, logistic regression and multivariable, conditional, logistic regression (including age, sex, BMI, HbAlc, and insulin treatment at baseline, obesity-related disease, and TWL 2 years after surgery) were used to assess risks reported as OR with $95 \%$ CI as measures of association. Socioeconomic variables were analyzed using univariable, logistic regression and multivariable, logistic regression with adjustment for patientspecific variables associated with the chance of achieving diabetes remission in the previous multivariable analysis (defined as $\mathrm{p}<0.05$ after correction for multiple calculations). The Bonferroni-Holm method was used to correct for multiple calculations when appropriate. ${ }^{25}$ Missing data were handled by multiple imputations (presented in the manuscript), while analyses based on listwise deletion are presented in online supplemental tables 1-3; however, only minor differences were observed.

SPSS Statistics V.25 was used for all statistical analyses.

\section{RESULTS}

During the inclusion period from 2007 to 2015, 8112 patients with T2D who underwent RYGB procedures were identified in the SOReg. After excluding 55 individuals who died within 2 years after surgery, 8057 patients remained in the study. At 2-year follow-up, weight and BMI were registered for 4997 patients $(62.0 \%)$. A registration of HbAlc 12-24 months after surgery was available for 6438 patients $(79.4 \%)$. The baseline characteristics of the study participants are presented in table 1 .

\section{Surgical data}

Most surgical procedures were laparoscopic $(n=7745$, $95.5 \%), 257$ were primary open procedures $(3.2 \%)$, and 110 were conversions to open surgery $(1.4 \%)$. Postoperative complications occurred in 821 operations (10.2\%). For patients operated after 2010, serious postoperative complications, requiring intervention under general

Table 2 Chance of reaching diabetes remission 2 years after surgery

\begin{tabular}{llll}
\hline & Unadjusted OR $(95 \%$ Cl) & Adjusted OR (95\% Cl)* & $\begin{array}{c}\text { Adjusted } \mathbf{p} \\
\text { value* }\end{array}$ \\
\hline Age & $0.95(0.94$ to 0.95$)$ & $0.97(0.96$ to 0.97$)$ & $<0.001$ \\
\hline Sex & & & Reference \\
\hline Female & Reference & $1.10(0.96$ to 1.26$)$ & 0.158 \\
\hline Male & $0.84(0.76$ to 0.93$)$ & $1.00(0.99$ to 1.01$)$ & 0.848 \\
\hline BMI & $1.05(1.04$ to 1.06$)$ & $0.89(0.88$ to 0.90$)$ & $<0.001$ \\
\hline Diabetes duration & $0.80(0.79$ to 0.81$)$ & $0.99(0.98$ to 0.99$)$ & $<0.001$ \\
\hline Glycosylated hemoglobin A1c & $0.97(0.96$ to 0.97$)$ & $0.26(0.22$ to 0.30$)$ & $<0.001$ \\
\hline Insulin treatment at baseline & $0.12(0.11$ to 0.14$)$ & $1.04(1.03$ to 1.04$)$ & $<0.001$ \\
\hline Percentage of total weight loss & $1.04(1.03$ to 1.05$)$ & & \\
\hline Obesity-related disease & & $0.71(0.62$ to 0.81$)$ & $<0.001$ \\
\hline Dyslipidemia & $0.42(0.37$ to 0.46$)$ & $0.99(0.83$ to 1.19$)$ & 0.927 \\
\hline Dyspepsia/GERD & $0.82(0.70$ to 0.95$)$ & $0.91(0.76$ to 1.07$)$ & 0.248 \\
\hline Depression & $0.93(0.81$ to 1.07$)$ & $1.02(0.87$ to 1.20$)$ & 0.785 \\
\hline Sleep apnea & $0.86(0.76$ to 0.98$)$ & $0.88(0.76$ to 1.01$)$ & 0.078 \\
\hline Hypertension & $0.48(0.43$ to 0.54$)$ & $0.98(0.82$ to 1.18$)$ & 0.864 \\
\hline Cardiovascular comorbidity & $0.55(0.48$ to 0.64$)$ & \\
\hline
\end{tabular}

*Multivariable logistic regression including all factors listed in the table, with multiple imputation for missing values.

$\mathrm{BMI}$, body mass index; GERD, gastroesophageal reflux disease. 


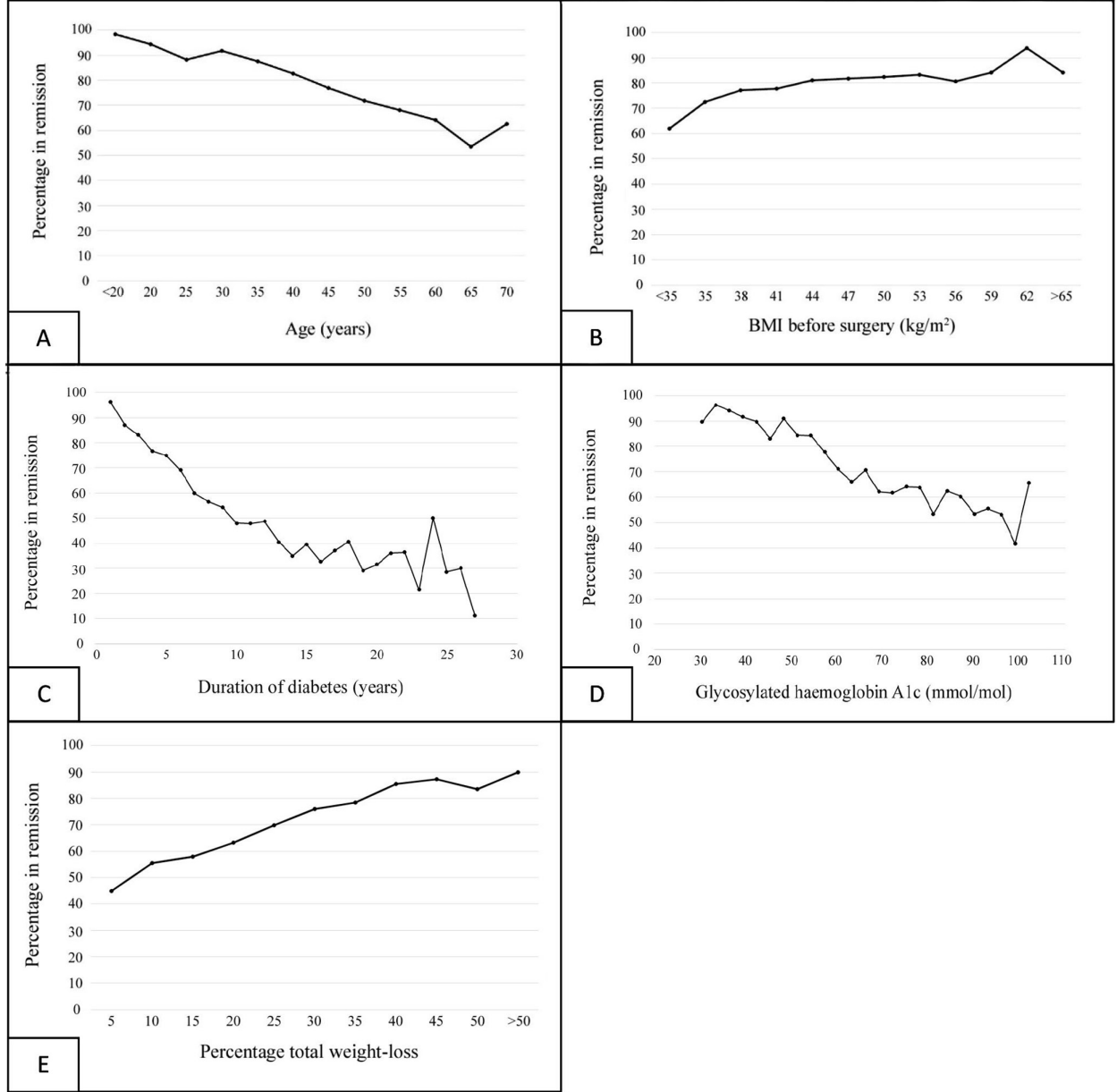

Figure 2 Association between continuous variables and cessation of treatment for T2D. Shown are age (A; Spearman coefficient $-0.21, p<0.0001$ ), BMI before surgery (B; Spearman coefficient $0.11, p<0.001$ ), duration of T2D (C; Spearman coefficient $-0.43, p<0.001$ ), glycosylated hemoglobin A1c ( $D$; Spearman coefficient $-0.28, p<0.001$ ), and postoperative total weight loss (E; Spearman coefficient 0.19, $\mathrm{p}<0.001)$. BMI, body mass index; T2D, type 2 diabetes.

anesthesia or intensive care, occurred in 223 operations $(2.7 \%)$. The mean BMI loss 2 years after surgery was $12.0 \pm 4.5 \mathrm{~kg} / \mathrm{m}^{2}$, with TWL of $28.4 \% \pm 8.9 \%$ and EBMIL of $73.3 \% \pm 24.4 \%$.

\section{Effects on diabetes}

At baseline, 2313 patients (28.7\%) were treated with insulin, while 3940 were given medical treatment not including insulin (48.9\%), and 1804 received nonpharmacological treatment only $(22.4 \%)$. Two years after surgery, 595 patients $(7.4 \%)$ received insulin treatment, 1251 received medical treatment not including insulin $(15.5 \%)$, and $6211(77.1 \%)$ received no treatment (figure 1).

Two years after surgery, 4004 patients $(62.2 \%)$ achieved complete diabetes remission, 680 patients $(10.6 \%)$ achieved partial remission, and 687 patients $(10.7 \%)$ had an HbAlc level $<48 \mathrm{mmol} / \mathrm{mol}$ with medical treatment, while 1067 patients (16.6\%) still had an HbAlc $\geq 48 \mathrm{mmol} / \mathrm{mol}$ on medical treatment.

Two years after surgery, 1129 patients (48.8\%) who received insulin at baseline did not receive pharmacological treatment for diabetes, compared with 5082 patients
(88.5\%) who were not receiving insulin at baseline, while 577 patients (24.9\%) initially receiving insulin still required insulin treatment at 2-year follow-up.

Age, BMI at baseline, duration of diabetes, preoperative HbAlc level, and postoperative weight loss were all continuous variables affecting the chance of diabetes remission in the univariable analyses (table 2). The association assumed a linear correlation for these variables (figure 2). No statistical association was observed for BMI in the multivariable analyses (table 2). The categorical variables insulin treatment at baseline and dyslipidemia were also negatively associated with diabetes remission (table 2).

\section{Socioeconomic factors}

The highest percentiles of disposable income were associated with a lower chance of reaching diabetes remission, but the association did not remain significant after correction for multiple calculations. Residence in a large city and being a first-generation immigrant were factors associated with a lower chance of achieving diabetes remission (table 3). 
Table 3 Chance of reaching diabetes remission depending on socioeconomic status

\begin{tabular}{|c|c|c|c|}
\hline & Unadjusted OR (95\% Cl) & Adjusted OR $(95 \% \mathrm{Cl}) \dagger$ & $\begin{array}{l}\text { Adjusted } p \\
\text { value } \dagger\end{array}$ \\
\hline \multicolumn{4}{|l|}{ Education } \\
\hline Primary education $\leq 9$ years & $0.92(0.81$ to 1.05$)$ & $0.96(0.82$ to 1.13$)$ & $1.000^{*}$ \\
\hline Secondary education & Reference & Reference & Reference \\
\hline Higher education $\leq 3$ years & 1.09 (0.91 to 1.31$)$ & $1.06(0.86$ to 1.31$)$ & $1.000^{*}$ \\
\hline Higher education $>3$ years & 1.07 (0.89 to 1.28$)$ & $1.00(0.80$ to 1.24$)$ & $0.891^{*}$ \\
\hline \multicolumn{4}{|l|}{ Disposable income } \\
\hline$<20$ th percentile & 0.93 (0.81 to 1.06$)$ & 0.86 (0.73 to 1.01$)$ & $0.116^{\star}$ \\
\hline 20th-50th percentile & Reference & Reference & Reference \\
\hline 50th-80th percentile & $1.00(0.87$ to 1.15$)$ & $0.98(0.84$ to 1.16$)$ & $0.796^{*}$ \\
\hline$>80$ th percentile & 0.83 (0.70 to 0.99$)$ & 0.80 (0.65 to 0.99$)$ & $0.069^{*}$ \\
\hline \multicolumn{4}{|l|}{ Residence } \\
\hline Large city and municipality (>200000 inhabitants) & Reference & Reference & Reference \\
\hline $\begin{array}{l}\text { Medium-sized town and municipality (50000- } \\
200000 \text { inhabitants) }\end{array}$ & 1.20 (1.06 to 1.35$)$ & $1.39(1.20$ to 1.61$)$ & $<0.001^{*}$ \\
\hline $\begin{array}{l}\text { Small town, urban area, rural municipality } \\
(<50000 \text { inhabitants })\end{array}$ & $1.20(1.05$ to 1.37$)$ & $1.46(1.25$ to 1.71$)$ & $<0.001^{*}$ \\
\hline \multicolumn{4}{|l|}{ Heritage } \\
\hline Swedish-born, Swedish descendant & Reference & Reference & \\
\hline Swedish-born, non-Swedish descendant & 1.10 (0.84 to 1.43$)$ & $0.82(0.60$ to 1.13$)$ & $0.235^{\star}$ \\
\hline Born outside Sweden & $0.80(0.70$ to 0.90$)$ & $0.66(0.57$ to 0.77$)$ & $<0.001^{\star}$ \\
\hline
\end{tabular}

${ }^{*} \mathrm{P}$ values after correction for multiple comparisons with the Bonferroni-Holm method.

†Adjusted for age, sex, BMI, insulin treatment at baseline, dyslipidemia, duration of diabetes, HbA1c at baseline, and \%TWL at 2-year follow-up, with multiple imputation for missing values.

BMI, body mass index; HbA1c, glycosylated hemoglobin A1c; \%TWL, percentage of total weight loss.

\section{DISCUSSION}

At 2-year follow-up after bariatric and metabolic surgery, we could verify several factors associated with a lower chance of T2D remission rate: duration of diabetes, HbA1c, and older age. However, being a first-generation immigrant and a resident in a large city was associated with lower remission rates. Large postoperative weight loss was associated with a better chance of diabetes remission.

High HbA1c at baseline, insulin treatment, longer duration of T2D, and metabolic comorbidities such as dyslipidemia all represented markers of poor control of metabolic diseases and had previously been described as factors associated with a lower chance of diabetes remission. ${ }^{13}$ A linear, inverse relationship between duration of diabetes and the chance of achieving remission has previously been suggested and was confirmed in this study. ${ }^{13}$ Moreover, we could demonstrate a similar linear inverse relationship regarding preoperative $\mathrm{HbA1c}$ and age, whereas we found a positive linear relationship between postoperative total weight loss and remission.

Age was previously reported to be negatively associated with the chance of achieving diabetes remission. ${ }^{13}$ Older patients were more likely to have obesity-related disease, less physically active, and achieved less weight loss after surgery than younger patients. An inverse linear correlation was observed between age and chance of T2D remission in this present study, although we did not find any clear cut-off. Even the group of patients aged $>60$ years showed a high remission rate (in our study as well as in the previous literature), suggesting that age should not limit access to bariatric and metabolic surgery. ${ }^{26}$

A longer duration of T2D, and disease severity, is usually associated with impaired beta-cell function and insulin resistance. Although the function of beta-cells may improve after bariatric surgery, damage can be irreversible. ${ }^{27}$ Even if some patients with severe T2D do not achieve complete remission, they may benefit from a reduction in insulin resistance and partial beta-cell recovery. Indeed, about $75 \%$ of patients with insulin treatment at baseline had discontinued insulin use 2 years after surgery.

The mechanisms of action mediating the positive effects of bariatric and metabolic surgery are only partially understood; however, weight loss is an obvious contributing factor. ${ }^{27} \mathrm{~A}$ high $\mathrm{BMI}$ at baseline is associated with high insulin resistance, and significant improvements in weight-dependent disease after surgery have previously been reported. In addition, the higher chance of diabetes remission in patients with higher BMI, seen 
in the present univariable analysis, disappeared in the multivariable analyses (including supplementary analysis with stratified BMI as presented in online supplemental tables 1-3), indicating that weight loss alone may be a more important factor than BMI.

In addition to previously known factors, this study suggested that socioeconomic factors are important determinants of the chance of diabetes remission after bariatric and metabolic surgery. First-generation immigrants had a lower chance of diabetes remission, as had patients residing in a larger city. An association between both of these factors and the risk of postoperative complications has been previously reported. ${ }^{18}$ Previous studies have reported lower weight loss and improvement in health-related quality of life, as well as higher loss to follow-up after bariatric surgery for patients living in larger cities. ${ }^{19} 2028$ While part of these findings may be explained by the chronic stress and higher cortisol levels of urban life, as well as the higher availability of energy-dense food, the cause of these negative associations remains largely unknown. ${ }^{29}$ However, low socioeconomic status and income are associated with poor health literacy, factors known to influence postoperative recovery and treatment compliance. ${ }^{30} 31$ Furthermore, access to healthcare may differ depending on socioeconomic status. We recently demonstrated that lower socioeconomic status precludes patients with T2D in general from having RYGB in Sweden. ${ }^{32}$ Further research is needed to understand these inequalities in health outcomes, but an enhanced perioperative and postoperative support for certain groups may improve long-term outcomes.

Diabetes currently causes the highest financial load on the healthcare system, with $>50 \%$ of costs being on medications. ${ }^{33}$ Although the initial costs of bariatric and metabolic surgeries are substantial, the subsequent overall reduction in diabetes medication and complications represents reduced costs over time, even with less effective surgical methods than those used today. ${ }^{34}$

Although the results of the present study suggest that younger patients with a short duration of diabetes and better glucose control before insulin treatment have the best chance of achieving diabetes remission, surgical treatment should not be discouraged for older patients with longer diabetes duration and/or poor diabetes control. These results contradict the widespread opinion that bariatric and metabolic surgery should be considered a 'last resort' when all other treatment options have failed. Metabolic surgery for patients with T2D should rather be considered early in the course of the disease. This has been concluded in the Swedish Obese Subjects Study and further emphasized in the Second Diabetes Surgery Summit recommendations. ${ }^{5} 35$ However, even patients not reaching full remission may benefit substantially from surgery, that is, reduction in dose and number of drugs (particularly insulin) and reduction in other comorbidities such as osteoarthritis and obstructive sleep apnea. Therefore, limited access to bariatric and metabolic surgeries based on age, BMI, and duration and severity of diabetes should be used with caution.

\section{Limitations}

The combination of several high-quality registers in this study provided almost complete follow-up with the highest quality data. However, the main limitation was our definition of remission based on medical treatment alone with no confirmation using laboratory values for the main outcome, potentially overestimating treatment effects. Patients in diabetes remission may remain on metformin because of their possible protection against cardiovascular events and relapse of disease, thus underestimating the correct remission rate. ${ }^{36}{ }^{37}$ In addition, follow-up for the main outcome was limited to 2 years. This short-term follow-up was decided because the majority of remission would occur during this period. A longer follow-up period would allow the inclusion of relapse of disease. C peptide has previously been reported as a factor associated with a reduced chance of achieving diabetes remission. ${ }^{38}$ Since $\mathrm{C}$ peptide is not generally registered in the SOReg, it could not be included in this study. Finally, due to the low historical number of sleeve gastrectomies in Sweden, only RYGB was evaluated. Although this has the strength of avoiding differences in associations and efficacy between surgical methods, it limits generalizability to the surgical method evaluated.

\section{CONCLUSION}

Among patients with T2D undergoing gastric bypass surgery, the overall remission rate, defined as being off medication, was $77 \%$. Factors known to be associated with a lower remission rate, such as duration of diabetes, older age, and severity of metabolic impairment, had a linear inverse relationship with remission of T2D. Some socioeconomic factors were also associated with a lower chance of achieving T2D remission in this study: firstgeneration immigrants and living in a large city. Large postoperative weight loss was associated with a better chance of remission.

\section{Author affiliations}

${ }^{1}$ Faculty of Medicine and Health, Örebro Universitet, Örebro, Sweden

${ }^{2}$ Department of Biomedical and Clinical Sciences and Wallenberg Center for Molecular Medicine, Linköping University, Linkoping, Sweden

${ }^{3}$ Department of Gastrosurgical Research, Sahlgrenska University Hospital, Goteborg, Sweden

${ }^{4}$ Clinical Epidemiology and Biostatistics, School of Medical Sciences, Örebro University, Orebro, Sweden

${ }^{5}$ Department of Surgical Sciences, Uppsala University, Uppsala, Sweden

${ }^{6}$ Division of Surgery, Department of Clinical Sciences, Karolinska Institutet, Stockholm, Sweden

Contributors ES, TO, EN, and IN planned and conceptualized the study. ES, JO, AJ, $\mathrm{EN}$, and IN were responsible for acquisition of data, while all authors contributed to interpretation of the results. ES and YC were responsible for statistical analyses. ES wrote the first draft. TO, YC, MS, AJ, JO, EN, and IN provided significant critical revision to the manuscript. All authors read and approved of the final manuscript.

Funding This work was supported by grants from Region Örebro County, Bengt Ihre Foundation, Stockholm County Council, SRP Diabetes, and Novo Nordisk 
Foundation. The funder of the study had no role in the study design, data collection, analysis, and interpretation, or writing of the report. The corresponding author had full access to all data in the study and was responsible for the decision to submit for publication.

Competing interests T0 has received reimbursement unrelated to the present study from Johnson \& Johnson, Novo Nordisk, Vifor Pharma, and Mölnlycke. All reimbursements were directed to his institution. $\mathrm{J} 0$ received consultant fees from Vifor Pharma and Ethicon Endo-Surgery, Johnson \& Johnson for work unrelated to the context of the present study. IN received consultant fees from Baricol Bariatrics, Sweden and Ethicon Endo-Surgery, Johnson \& Johnson for work unrelated to the context of the present study. None of the remaining authors declared any conflict of interest.

\section{Patient consent for publication Not required.}

Ethics approval The study was approved by the Regional Ethics Committee in Stockholm (DNR 2013/535-31/5, 2014/1639-32, and 2017/857-32) and was conducted in accordance with the ethical standards of the 1964 Helsinki Declaration and its later amendments. In accordance with the current Swedish legislation, all patients were informed of registration in the SOReg and that data from the register would be used in clinical research, giving patients the right to decline participation or to have registered data withdrawn at any time.

Provenance and peer review Not commissioned; externally peer reviewed.

Data availability statement Data may be obtained from a third party and are not publicly available. Data cannot be shared publicly due to patient confidentiality under current Swedish legislation. Data are available from the Scandinavian Obesity Surgery Registry (contact via www.ucr.uu.se/soreg/) for researchers who meet the criteria for access to confidential data.

Supplemental material This content has been supplied by the author(s). It has not been vetted by BMJ Publishing Group Limited (BMJ) and may not have been peer-reviewed. Any opinions or recommendations discussed are solely those of the author(s) and are not endorsed by BMJ. BMJ disclaims all liability and responsibility arising from any reliance placed on the content. Where the content includes any translated material, BMJ does not warrant the accuracy and reliability of the translations (including but not limited to local regulations, clinical guidelines, terminology, drug names and drug dosages), and is not responsible for any error and/or omissions arising from translation and adaptation or otherwise.

Open access This is an open access article distributed in accordance with the Creative Commons Attribution 4.0 Unported (CC BY 4.0) license, which permits others to copy, redistribute, remix, transform and build upon this work for any purpose, provided the original work is properly cited, a link to the licence is given, and indication of whether changes were made. See: https://creativecommons.org/ licenses/by/4.0/.

ORCID iDs

Erik Stenberg http://orcid.org/0000-0001-9189-0093

Yang Cao http://orcid.org/0000-0002-3552-9153

Magnus Sundbom http://orcid.org/0000-0002-6243-2859

Anders Jans http://orcid.org/0000-0002-3721-5246

Ingmar Näslund http://orcid.org/0000-0002-3644-3319

\section{REFERENCES}

1 Danaei G, Finucane MM, Lu Y, et al. National, regional, and global trends in fasting plasma glucose and diabetes prevalence since 1980: systematic analysis of health examination surveys and epidemiological studies with 370 country-years and $2 \cdot 7$ million participants. Lancet 2011;378:31-40.

2 Magliano DJ, Islam RM, Barr ELM, et al. Trends in incidence of total or type 2 diabetes: systematic review. BMJ 2019;366:I5003.

3 Bellou V, Belbasis L, Tzoulaki I, et al. Risk factors for type 2 diabetes mellitus: an exposure-wide umbrella review of meta-analyses. PLoS One 2018;13:e0194127.

4 GBD 2015 Obesity Collaborators, Afshin A, Forouzanfar MH, et al. Health effects of overweight and obesity in 195 countries over 25 years. N Engl J Med 2017;377:13-27.

5 Sjöström L, Peltonen M, Jacobson P, et al. Association of bariatric surgery with long-term remission of type 2 diabetes and with microvascular and macrovascular complications. JAMA 2014;311:2297-304.

6 Sundbom M, Hedberg J, Marsk R, et al. Substantial decrease in comorbidity 5 years after gastric bypass: a population-based study from the Scandinavian obesity surgery registry. Ann Surg 2017;265:1166-71.

7 Stenberg E, Szabo E, Agren G, et al. Early complications after laparoscopic gastric bypass surgery: results from the Scandinavian obesity surgery registry. Ann Surg 2014;260:1040-7.

8 Schauer PR, Bhatt DL, Kirwan JP, et al. Bariatric surgery versus intensive medical therapy for diabetes - 5-year outcomes. $N$ Engl J Med 2017;376:641-51

9 Mingrone G, Panunzi S, De Gaetano A, et al. Bariatric-metabolic surgery versus conventional medical treatment in obese patients with type 2 diabetes: 5 year follow-up of an open-label, singlecentre, randomised controlled trial. Lancet 2015;386:964-73.

10 Aminian A, Vidal J, Salminen P, et al. Late relapse of diabetes after bariatric surgery: not rare, but not a failure. Diabetes Care 2020;43:534-40.

11 Wan B, Fang N, Guan W, et al. Cost-effectiveness of bariatric surgery versus medication therapy for obese patients with type 2 diabetes in China: a Markov analysis. J Diabetes Res 2019;2019:1341963

12 Ahmad A, Laverty AA, Aasheim E, et al. Eligibility for bariatric surgery among adults in England: analysis of a national cross-sectional survey. JRSM Open 2014;5:204253331351247.

13 Jans A, Näslund I, Ottosson J, et al. Duration of type 2 diabetes and remission rates after bariatric surgery in Sweden 2007-2015: a registry-based cohort study. PLoS Med 2019;16:e1002985.

14 Pessoa BM, Browning MG, Mazzini GS, et al. Factors mediating type 2 diabetes remission and relapse after gastric bypass surgery. J Am Coll Surg 2020;230:7-16.

15 Arterburn DE, Bogart A, Sherwood NE, et al. A multisite study of long-term remission and relapse of type 2 diabetes mellitus following gastric bypass. Obes Surg 2013;23:93-102.

16 National Institute for Health and Care Excellence. Obesity: identification, asessment and management 2014.

17 Kyrou I, Tsigos C, Mavrogianni C, et al. Sociodemographic and lifestyle-related risk factors for identifying vulnerable groups for type 2 diabetes: a narrative review with emphasis on data from Europe. BMC Endocr Disord 2020;20:134.

18 Stenberg E, Persson C, Näslund E, et al. The impact of socioeconomic factors on the early postoperative complication rate after laparoscopic gastric bypass surgery: a register-based cohort study. Surg Obes Relat Dis 2019;15:575-81.

19 Stenberg E, Näslund I, Persson C, et al. The association between socioeconomic factors and weight loss 5 years after gastric bypass surgery. Int J Obes 2020;44:2279-90.

20 Gryth K, Persson C, Näslund I, et al. The influence of socioeconomic factors on quality-of-life after laparoscopic gastric bypass surgery. Obes Surg 2019;29:3569-76.

21 Hedenbro JL, Näslund E, Boman L, et al. Formation of the Scandinavian obesity surgery registry, SOReg. Obes Surg 2015;25:1893-900

22 American Diabetes Association. Diagnosis and classification of diabetes mellitus. Diabetes Care 2014;37:S81-90.

23 Clavien PA, Barkun J, de Oliveira ML, et al. The Clavien-Dindo classification of surgical complications: five-year experience. Ann Surg 2009;250:187-96.

24 Brethauer SA, Kim J, El Chaar M, et al. Standardized outcomes reporting in metabolic and bariatric surgery. Surg Obes Relat Dis 2015;11:489-506.

25 Holm S. A simple sequentially Rejective multiple test procedure. Scand J Statist 1979;6:65-70.

26 Vallois A, Menahem B, Alves A. Is Laparoscopic Bariatric Surgery Safe and Effective in Patients over 60 Years of Age?" an Updated Systematic Review and Meta-Analysis. Obes Surg 2020;30:5059-70.

27 Stenberg E, Thorell A. Insulin resistance in bariatric surgery. Curr Opin Clin Nutr Metab Care 2020;23:255-61.

28 Kedestig J, Stenberg E. Loss to follow-up after laparoscopic gastric bypass surgery - a post hoc analysis of a randomized clinical trial. Surg Obes Relat Dis 2019;15:880-6.

29 Zarzycka D, Ślusarska B, Marcinowicz L, et al. Assessment of differences in psychosocial resources and state of health of rural and urban residents-based on studies carried out on students during examination stress. Ann Agric Environ Med 2014;21:882-7.

30 Hälleberg Nyman M, Nilsson U, Dahlberg K, et al. Association between functional health literacy and postoperative recovery, health care contacts, and health-related quality of life among patients undergoing day surgery: secondary analysis of a randomized clinical trial. JAMA Surg 2018;153:738-45.

31 Protheroe J, Whittle R, Bartlam B, et al. Health literacy, associated lifestyle and demographic factors in adult population of an English City: a cross-sectional survey. Health Expect 2017;20:112-9. 
32 Sundbom M, Franzén S, Ottosson J, et al. Superior socioeconomic status in patients with type 2 diabetes having gastric bypass surgery: a case-control analysis of 10642 individuals. BMJ Open Diabetes Res Care 2020;8:e000989.

33 Dieleman JL, Baral R, Birger M, et al. Us spending on personal health care and public health, 1996-2013. JAMA 2016;316:2627-46.

34 Keating C, Neovius M, Sjöholm K, et al. Health-care costs over 15 years after bariatric surgery for patients with different baseline glucose status: results from the Swedish obese subjects study. Lancet Diabetes Endocrinol 2015;3:855-65.
35 Rubino F, Nathan DM, Eckel RH, et al. Metabolic surgery in the treatment algorithm for type 2 diabetes: a joint statement by international diabetes organizations. Diabetes Care 2016;39:861-77.

36 Luo F, Das A, Chen J, et al. Metformin in patients with and without diabetes: a paradigm shift in cardiovascular disease management. Cardiovasc Diabetol 2019;18:54.

37 Souteiro P, Belo S, Magalhães D, et al. Long-term diabetes outcomes after bariatric surgery-managing medication withdrawl. Int $J$ Obes 2019;43:2217-24.

38 Lee W-J, Hur KY, Lakadawala M, et al. Predicting success of metabolic surgery: age, body mass index, C-peptide, and duration score. Surg Obes Relat Dis 2013;9:379-84. 